\title{
ОРГАНИЗАЦИОННО-УПРАВЛЕНЧЕСКИЕ ВОПРОСЫ СОЗДАНИЯ КОНТРОЛЛИНГОВОГО ЦЕНТРА МУНИЦИПАЛЬНОГО ОБРАЗОВАНИЯ
}

\section{ORGANIZATIONAL AND MANAGERIAL ISSUES OF CREATING A CONTROLLING CENTER OF A MUNICIPALITY}

\section{Pavlenkov}

Summary. The article deals with the organizational and managerial issues of creating a controlling center of a municipality, as a basis for the development of organizational and methodological support for the coordination of the activities of a municipality based on the introduction of new methods and mechanisms. The organizational and management requirements, the technology of creation and the structure of the controlling center of the municipality have been developed.

Keywords: municipal formation, management, controlling, management functions, management structures.
Павленков Иван Михайлович

К.э.н., ректор, Нижегородский институт развития образования

kaf-fin-df@yandex.ru

Аннотация. В статье рассмотрены организационно-управленческие вопросы создания контроллингового центра муниципального образования, как база развития организационно - методического обеспечения координации деятельности муниципального образования на основе внедрения новых методов и механизмов. Разработаны организационно-управленческие требования, технология создания и структура контроллингового центра муниципального образования.

Ключевые слова: муниципальное образование, управление, контроллинг, функции управления, структур управления.

\section{Введение}

$\mathbf{M}$ униципальная экономика в условиях развития рыночных отношений нуждается и в развитии рыночных институтов, в том числе и структур управления. Повышение роли планирования муниципальным образованием, необходимость усиления координации всех подразделений как внутри, так и с внешними организациями, обеспечение при этом достоверной и качественной информацией для оценки состояния и принятия эффективных решений на разных уровнях управления, должны основываться на внедрении новых механизмов анализа, планирования и оперативного регулирования, а для этого необходимо совершенствовать организацию управления муниципальным образованием $[4,6,9,15]$.

Менеджмент структурных подразделений, исходя из своих функций, не может решить индивидуально изменять принципы управления муниципальным образованием, цели развития муниципального образования и функции, реализующие эти цели, решаемые задачи и механизмы управления деятельностью муниципального образования. Все это требует разработки новых подходов к взаимодействию подразделений в общей структуре управления муниципальным образованием и методических проработок координации взаимодействия с внешними организациями. В первую очередь

это относится к взаимодействию с органами власти верхнего уровня.

Для решения, возникающих проблем в управлении, разработке эффективных решений, использования ограниченных муниципальных ресурсов, внедрения современных программных систем и информационных технологий, широкого использования мониторинга планов социально - экономического развития, развития организационно - методического обеспечения и других проблем управления необходимо совершенствовать существующую систему управления.

\section{Организационно-управленческие вопросы созАания контроммингового чентра}

В целях повышения эффективности работы подразделений муниципального образования в целом необходимо создать “ Контроллинговый центр», который для повышения его значимости в системе управления должен непосредственно быть подчинен главе муниципального образования (рисунок 1).

Контроллинговый центр муниципального образования создается как база развития организационно методического обеспечения, а так же для внедрения новых методов и механизмов обоснования плановых решений на текущий и перспективные периоды. По- 


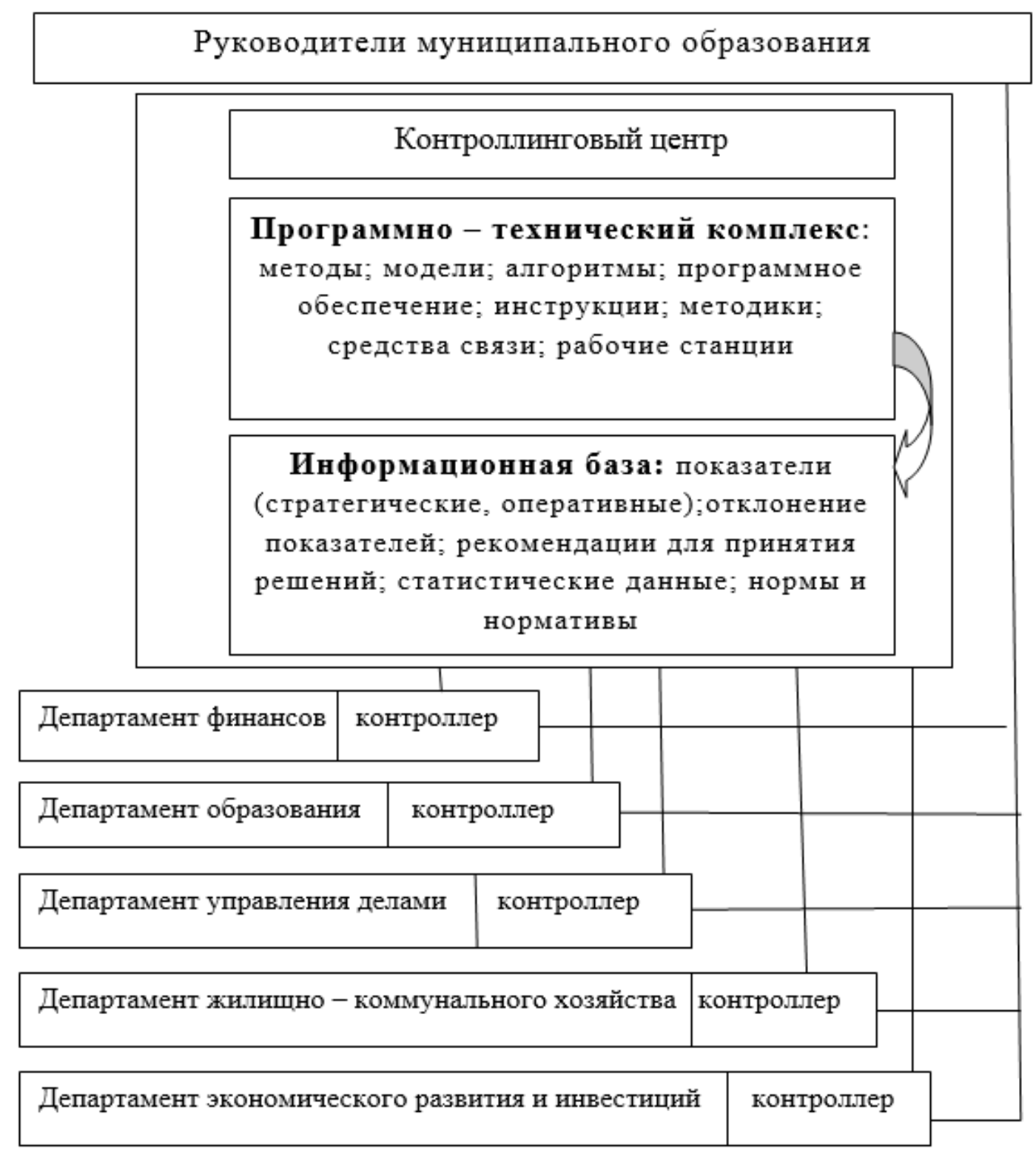

Рис. 1. Контроллинговый центр муниципального образования

требность муниципального образования в использовании новых механизмов и инструментов диктуется изменяющимися факторами внешней среды, что требует от менеджмента принятия часто быстрых неординарных решений $[1,2,5,10,13]$. Для оценки и обеспечения принятия решений необходимо иметь достоверную информацию. Одним из эффективных инструментов контроллинга является мониторинг, с помощью которого проводится сбор информации:

- показателей внешней среды;

- оперативных показателей внутренней среды.
Для эффективного и оперативного решения муниципальных задач нужно:

- разработать информационную базу муниципального образования;

- разработать базу методов и моделей для решения задач муниципального образования;

- внедрить мониторинг функционирования муниципального образования;

- создать организационно - экономическую систему координации муниципального образования. 
Для эффективного взаимодействия со специалистами муниципального образования контроллеры должны владеть дополнительными классическими компетенциями, которые определены в ICV\&IGC как базисные [16]:

1. «Функция локомотива». Центр не ставит задачу получения дополнительной прибыли, а вот предложения по снижению затрат на решение муниципальных вопросов могут генерировать, устанавливая совместно с руководством показатели $[1,11]$.

Функция эта реализуется в результате партнерства со специалистами муниципального образования, поэтому контроллинг является разработчиком и поставщиком методик, аналитической информации для руководства различного уровня муниципального образования. Следовательно, к традиционным компетенциям проявляется компетентность ценностно-ориентированного мышления, что способствует взаимодействию со специалистами при генерировании результатов $[1,3,12,15]$.

2. «Функция согласования. Данная функция относится ко всему циклу управления: определение и согласование целей, показателей, планов, последовательности реализации, процессов выполнения учетно-контрольных функций и корректирующих мероприятий» $[1,7,14,16]$.

Функционально контроллинг участвует в решении многих вопросов муниципального образования, таких как:

- обоснование целей развития муниципального образования;

- формирование планов развития муниципального образования;

- оценка отклонений достигнутых значений от установленных показателей.

Компетенции контроллеров дополняются за счет:

- базовых знаний системного анализа, основ теории иерархий, теории и практики математических методов;

- умения применять теоретические знания при разработке моделей социально - экономических систем различного уровня.

3. «Информационная функция. Контроллинг должен обеспечить предоставление информации и удовлетворение запроса в ней менеджеров» $[1.8,12]$.

По различным каналам в контроллинговый центр поступает и обрабатывается значительный объем информации, а это возможно лишь на платформе информационных технологий. Другими словами, компетенции выражаются:
- в знании информационных технологий обработки информации;

- владении современными методами и языками программирования;

- умении проектировать интегрированные системы управления.

Функции, которые выполняют контроллеры не противоречат и не заменяют функции, которые выполняют менеджеры. В контроллинговом центре не формируют информацию для личных нужд, а обеспечивают качественной информацией руководителей и специалистов муниципального образования.

К важным, решаемым в контроллинговом центре задачам, можно отнести:

- выявление и разработка рекомендаций по устранение негативных экономических, социальных, экологических явлений в муниципальном образовании;

- нацеливание менеджмента муниципального образования на достижение конечных текущих и стратегических результатов.

В системе контроллинга для планирования, оценки состояния и разработки эффективных решений необходима оперативная и качественная система информации.

Важной задачей контроллингового центра является сбор и качественная обработка информации.

Создание системы контроллинга муниципального образования и ее внедрение является финансово затратным и трудоемким.

На процесс внедрения оказывают влияние такие факторы, как:

- поддержка высшего руководства муниципального образования;

- уровень восприятия специалистами философию контроллинга муниципального образования;

- заинтересованность и непосредственное участие менеджмента.

Для разработки контроллинга необходимы специалисты:

- с опытом практической работы в муниципалитете;

- владеющие знаниями муниципального управления;

- знающие методы анализа и системы планирования и прогнозирования;

- умеющие моделировать социально - экономические процессы; 
Этап 1. Обоснование необходимости разработки контроллинга

Технико - экономический анализ и определение миссии контроллинга

Разработка концепции контроллинга

Определение стратегических целей создания контроллинга управления

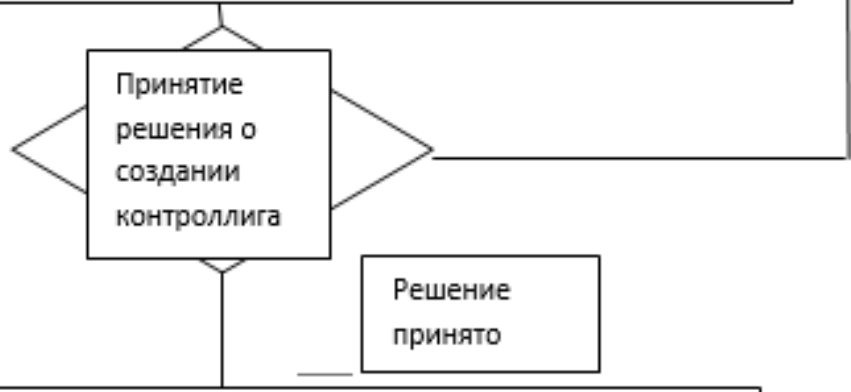

Этап 2. Разработка системы контроллинга управления

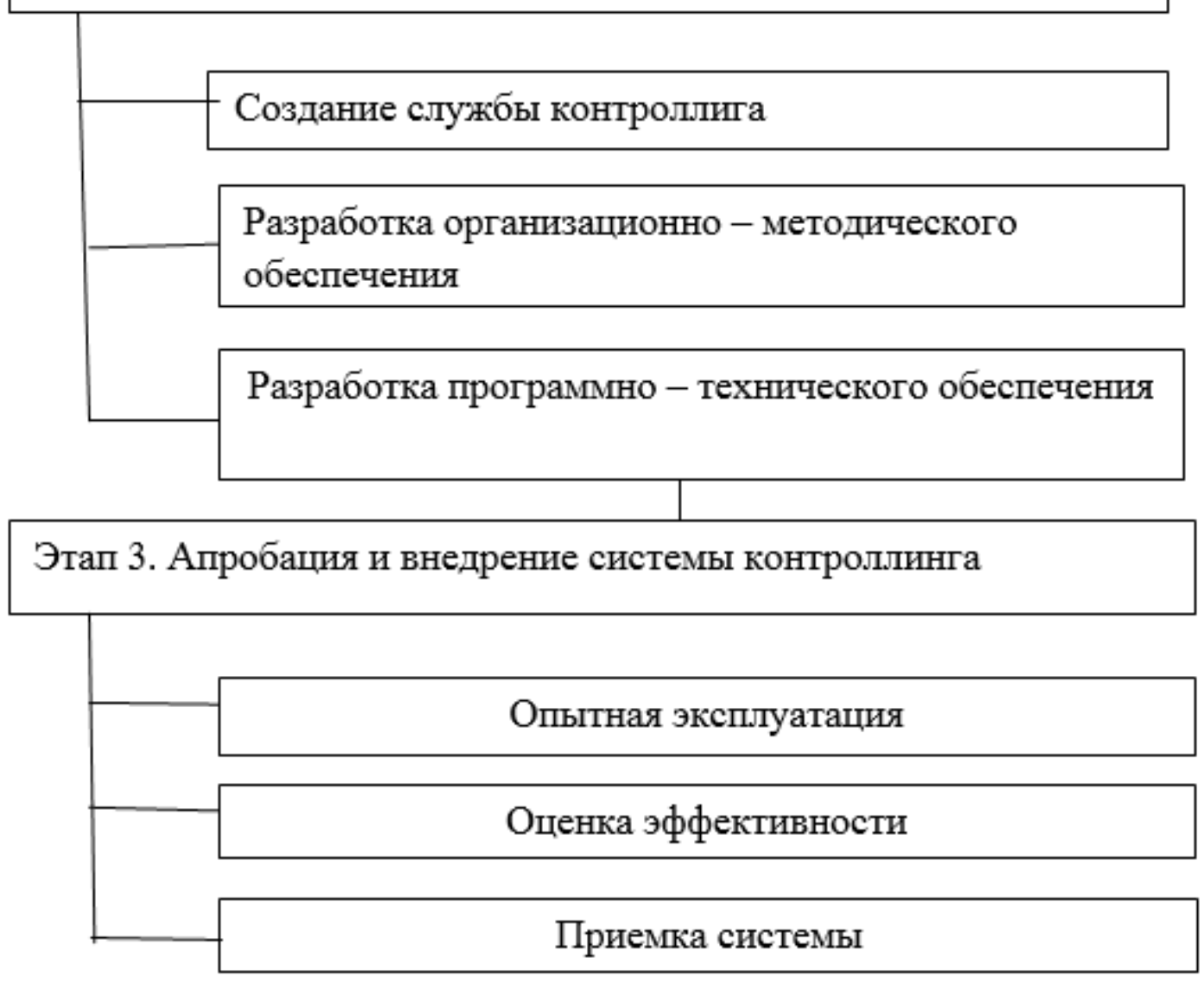

Рис. 2. Технология создания контроллинга управления муниципального образования 


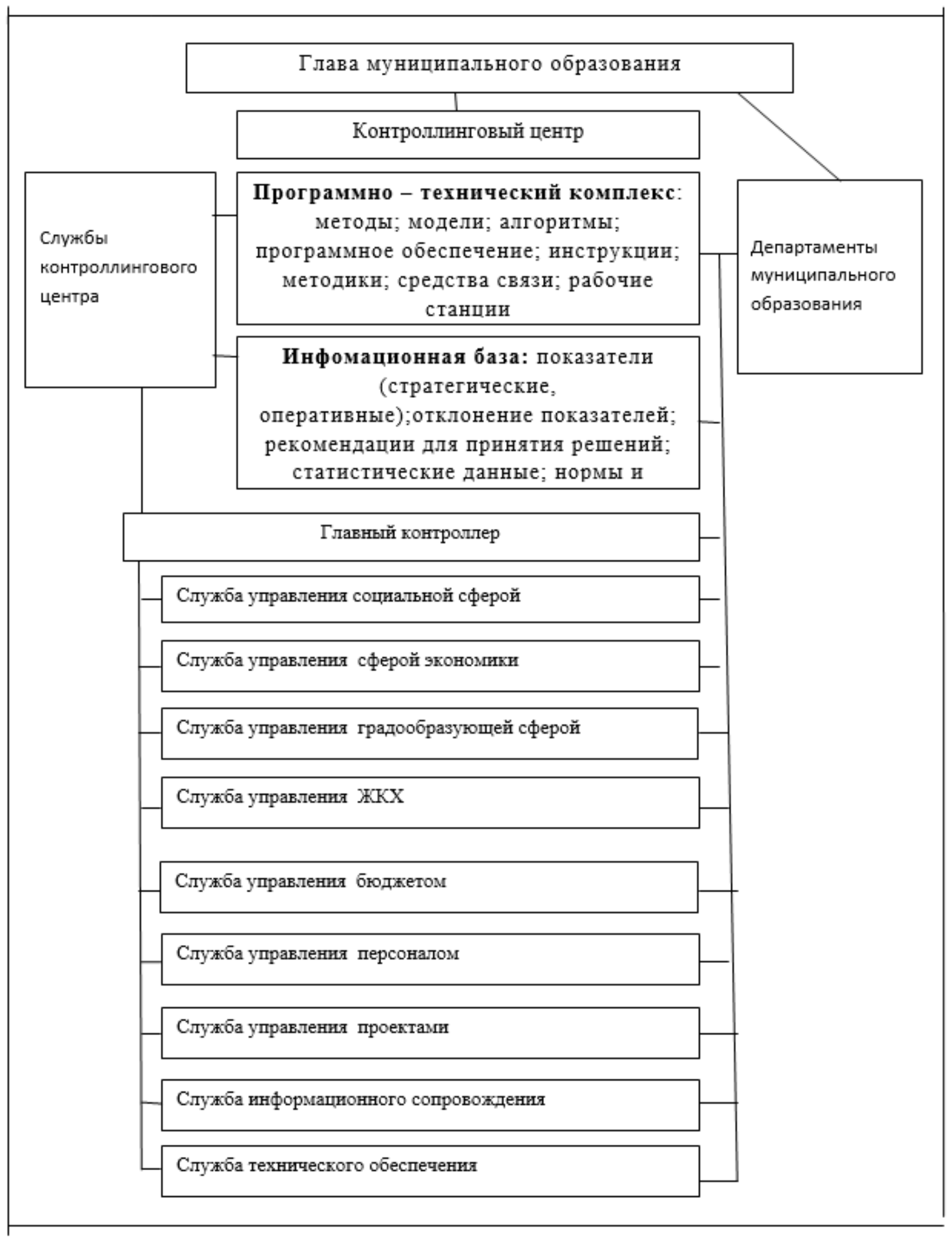

Рис. 3. Структура контроллингового центра 
- обладающие знаниями современных информационных технологий;

- обладающие системным мышлением;

- умеющие аналитически мыслить.

Знания и профессионализм руководителя контроллингового центра является важным фактором при создании и внедрении системы контроллинга муниципального образования. Главный контроллер муниципального образования должен иметь значительный опыт работы в муниципальном образовании, знать специфику и особенности процессов управления. От этого зависит эффективная работа контроллингового центра.

Весь процесс создания системы контроллинга должен быть с учетом особенностей муниципального образования регламентирован. В процессе создания для качественного формирования функций необходимо привлечь специалистов подразделений муниципального образования, что обеспечит объективно воспринимать цели создаваемой системы контроллинга, уточнить информационные связи и потоки между различными службами, а так же нивелировать разногласия, которые могут возникнуть в терминологии.

Важной задачей является подготовка менеджеров и исполнителей к восприятию нововведения в системе управления муниципальным образованием, что уменьшит недоверие к нововведениям.

Успех зависит во многом от эффективного взаимодействия подразделений муниципального образования с контроллинговым центром.

Технология создания контроллинга управления муниципального образования показана на рисунке 2, а на рисунке 3 структура контроллингового центра.

1. Разработка основ включает мероприятия:

- формирование принципов функционирования контроллинга;

- определение оперативных и стратегических целей;

- формирование функционального наполнения контроллинга;

- требование к наполнению задачами функционального содержания;
- определению методов реализации задач;

- по составу и содержанию информационного обеспечения;

- по программно техническому содержанию.

2. Формирование системы. Разрабатываются:

- миссия муниципального образования;

- требования к системе контроллинга;

- распорядительные документы по разработке системы контроллинга

- организационная структура контроллингового центра;

- функциональная структура контроллингового центра;

- состав и содержание нормативной базы;

- анализируется и разрабатывается набор методов и инструментов.

3. Внедрение. Оцениваются варианты и эффективность внедрения системы контроллинга.

Важнейшей задачей в процессе создания системы контроллинга

муниципального образования является задача формирования структуры управления контроллингового центра, который в процессе функционирования обеспечивает оперативный и качественный информационный обмен.

\section{Выводы}

1. Контроллинговый центр должен быть независимой структурой и подчиняться главе города.

2. «Контроллинговый центр» создается как база развития организационно - методического обеспечения координации деятельности муниципального образования на основе внедрения новых методов и механизмов.

3. Разработаны организационно-управленческие требования, технология создания и структура контроллингового центра муниципального образования, что позволяет адаптировать контроллинговые методы и инструменты, существующие в международной и отечественной практике, применить эти методы и инструменты, учитывая российскую специфику и особенности управления на муниципальном уровне, в совершенствовании управления муниципальным образованием.

\section{ЛИТЕРАТУРА}

1. Контроллинг. Карминский А.М., Фалько С.Г., Жевага А.А., Иванова Н.Ю. Учебник / Карминский А.М., Фалько С.Г., Жевага А.А., Иванова Н.Ю./-М.: 2013.

2. Ларионов В.Г., Фалько С.Г. Контроллинг в сфере охраны окружающей среды и экологической безопасности// Вестник Академии. 2013.

3. Орлов, А.И. Эконометрическая поддержка контроллинга // Контроллинг. - 2002. — № 1. — C. 42-53.

4. Павленков И.М. Программный подход к стимулированию развития муниципального образования. Инновации в менеджменте. 2018. № 3 (17). С. $44-53$. 
5. Павленков И.М. Контроллинг в системе управления муниципального образования. Контроллинг. 2018. № 68. С. 36-45.

6. Павленков И.М. Исследование закономерностей и принципов контроллинга управления муниципальным образованием. Экономика и менеджмент систем управления. 2018. № 3-2 (29). С. 255-263.

7. Павленков И.М. Методы контроллинга реализации функций муниципального образования. Московский экономический журнал. 2019. № 12. С. 88.

8. Павленков И.М. Проблемы и задачи информатизации процессов управления муниципального образования. Инновации в менеджменте. 2018. № 1 (15). C. 42-49.

9. Совершенствование механизмов управления социально-экономическим развитием муниципального образования / И.М. Павленков [и др.]. Н. Новгород: НИУ РАНХиГС, 2013.-306 С.

10. Трифонов, Ю.В. Стратегическое управление в рыночной экономике: монография / Ю.В. Трифонов [и др.]. — Н. Новгород: Изд-во ННГУ, 2003.

11. Фалько С.Г. Предмет контроллинга как самостоятельной научной дисциплины // Контроллинг. 2005. № 13. С. 2-6.

12. Фалько С.Г. Контроллинг: миссия, современное состояние и перспективы развития//Управляем предприятием. 2013. № 7. С. 1.

13. Фалько С.Г., Ассадулин Р.А. Перспективы развития контроллинга // Контроллинг. 2006. № 19. С. 10-13.

14. Фалько С.Г. 0 важности системного проектирования// Инновации в менеджменте. 2018. № 2 (16). С. 2.

15. Хан, Д. Стоимостно-ориентированные концепции контроллинга / Д. Хан; пер. с нем.- М.: Финансы и статистика, 2005. - 928 с.

16. www.controllerakademie.de

(c) Павленков Иван Михайлович ( kaf-fin-df@yandex.ru ).

Журнал «Современная наука: актуальные проблемы теории и практики»

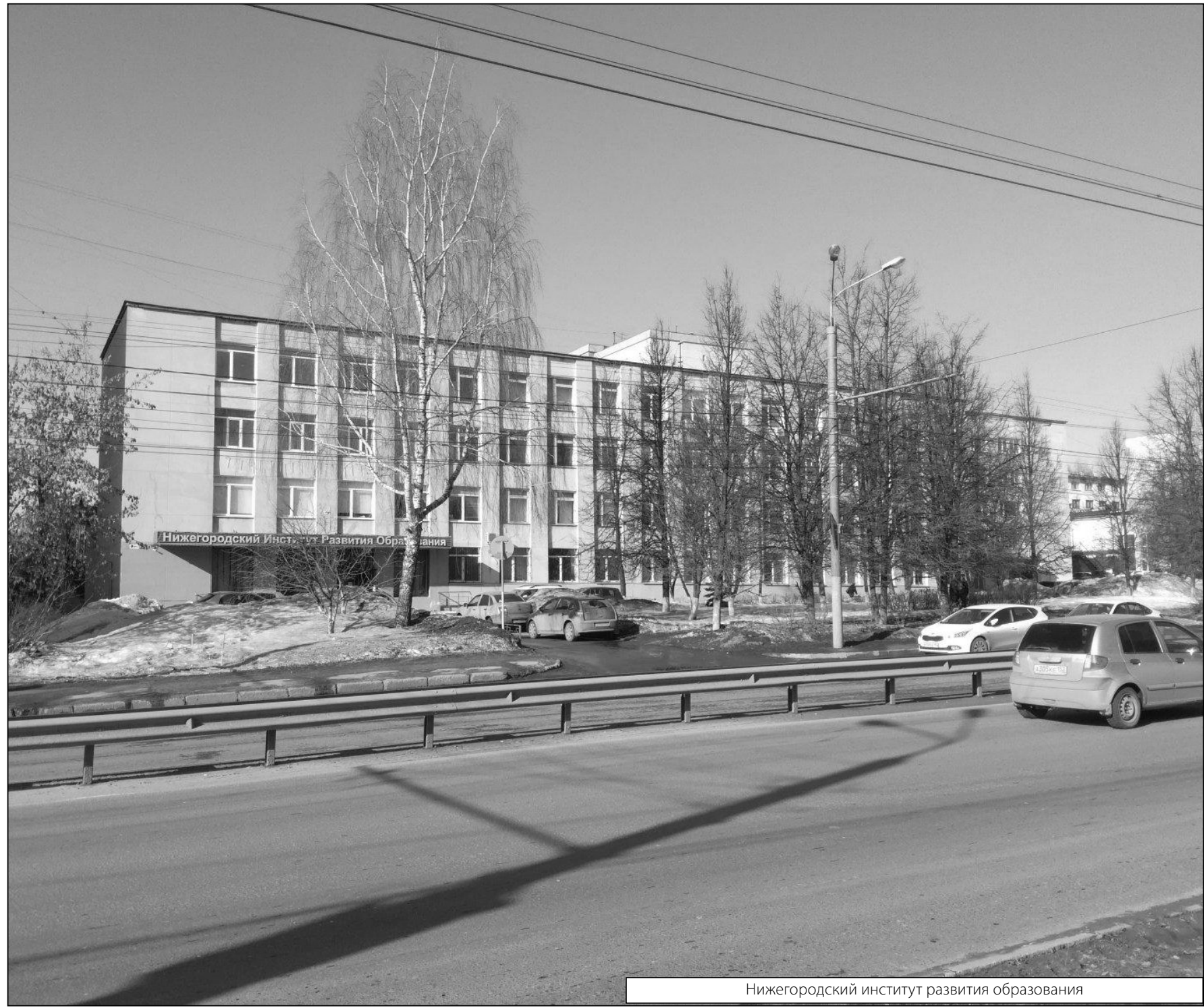

